\title{
ON-LINE PRACTICES IN DIGITAL ELECTRONICS: THE REMOTELAB EXPERIENCE
}

\author{
J. Ibáñez Civera, N. Laguarda Miró, L. Gil Sánchez, J.M. Terrés Haro, J. Monreal \\ Trigo, C.A. Olguín Pinatti \\ Universitat Politècnica de València (SPAIN)
}

\begin{abstract}
Higher Education is given on-line since COVID-19 appeared and disseminated all over the world. Both students and teachers had little time to adapt to new learning-teaching applications and tools such as TEAMS or ZOOM. Subsequently, learning methodologies were also redesigned to be effective in a "nonpresential" scenario that is mainly aseptic and depersonalized.
\end{abstract}

When the state of emergency and confinement were over, the University had to reinvent educational methodologies. Then, new educational terms and expressions appeared in Higher Education and particularly in Engineering careers. Terms such as "partial attendance", "synchronous and asynchronous sessions" are nowadays present in our course guidelines but also in an unstable scenario in which higher education strategies are changing by the day.

In this scenario, theory lessons have been easy to adapt to on-line education. In the same way, tutorials have become more fluid and flexible with this new system. On the other hand, difficulties to achieve an objective evaluation and conducting useful practice sessions are some of the identified weaknesses of the system.

This paper focuses on these aspects studying the development of practices by local or on-line simulators and even by remote laboratories. A specific practice prototype is introduced, allowing "partial attendance" of the students, a part of them in-situ in the laboratory and another part attending the practice on-line by remote access to the practice board. This proposal lets us develop real practices with no need of synchronous assistance from the teachers by using a remote system and monitoring its development by webcam.

Keywords: Higher education, Engineering, On-line practices, RemoteLab.

\section{INTRODUCTION}

As COVID-19 appeared and the state of alarm lead to a general confinement of the Spanish people in March 2020, academic activity began to be conducted virtually for both, students and teachers. In a very short period, we all had to adapt to new teaching tools such as TEAMS or ZOOM and change the learning-teaching methods from those designed for face-to-face session to others more aseptic and depersonalized but better for an on-line learning scenario.

The end of the first wave of the pandemics and the state of alarm in Spain, forced the Universities to reinvent teaching methodologies (at least in technical Degrees) giving birth to new concepts and expressions such as semi-presential, synchronous and asynchronous classes, etc. These new ideas and concepts are nowadays into force in the present Spanish Higher Education reality, that is unstable and changing; a scenario in which concepts that are mandatory today maybe tomorrow are out of date.

In this Spanish Higher Education environment, theoretical lectures were easy to adapt to a virtual online teaching. Tutorials were also easily adaptable and probably they are nowadays more fluent and accessible for the students. On the other hands, objective assessment of the students' work and presential laboratory practices are some of the weaknesses of this virtual scenario.

The limitation in the number of students simultaneously present in a classroom and safety distance maintenance are remarkable measurements to fight the COVID-19 dissemination but also difficult teamworking and simultaneous assistance to the laboratory sessions.

This work faces the above-mentioned aspects and introduces remote laboratories as an alternative to successfully carry out team working and laboratory practices by using local or remote simulators. Additionally, a practice prototype is presented, aiming to allow face-to-face interactions among students while working in small groups, some of them at home and some others in the classroom, but all of them 
accessing simultaneously to the same practice board. This prototype supports carrying out real practices in a virtual non supervised scenario but being directly monitored by webcam.

\section{METHODOLOGY AND APPLICATION FRAMEWORK}

The introduced proposal is expected to be implemented during the second semester of the 2020-2021 academic year. Specifically, in the second-year subject "Digital Electronics" of the Bachelor's Degree in Industrial Electronics and Automation Engineering given in the Design Engineering School (ETSID) at the Polytechnic University of Valencia (UPV). As a general overview, the competences achieved by the students in the subject are shown in table 1.

Table 1. Students' outcomes in Digital Electronics. In bold those associated to the subject

\begin{tabular}{c|l}
\hline \hline General Matter & \multicolumn{1}{c}{ Outcomes } \\
\hline \multirow{5}{*}{$\begin{array}{c}\text { Industrial } \\
\text { Electronics }\end{array}$} & Knowing general aspects and fundamentals of digital electronics and microprocessors \\
\cline { 2 - 2 } & Ability to design and simulate systems. \\
\cline { 2 - 2 } & $\begin{array}{l}\text { Ability to design analogic, digital and power electronic systems } \\
\text { objectives are: building, redesigning, repairing, maintaining, demolition, construction, } \\
\text { installing and exploitation of structures, mechanical machines, power plants, electric and } \\
\text { electronic systems, industrial plants, processes and automation systems. }\end{array}$ \\
\hline \hline
\end{tabular}

Additionally, the development of the transversal competence $n^{\circ} 4$ of the Transversal Competence Project at the UPV is associated to Digital Electronics [1-5]. So, innovation, creativity and entrepreneurship of the students are developed in the subject. To do so, the design and construction of a digital electronic system and specifically a control app for a small robot vehicle is proposed.

In this stage of the degree, the students have already been enrolled in a first semester subject called Electronic Technology and have learned about general aspects of digital electronics. Therefore, the acquisition of the associated competences is linked to the development of both subjects. Specifically, the program for Digital Electronics is divided into three sections as follows:

- Section I. Discrete digital systems (Input / Output couplings, clock circuits, synchronous sequential design, programmable logic devices)

- Section II. Microcontrollers (ATMEGA 328P)

- Section III. Development of a project [6] (competition vehicle, for transversal competition).

Given the current pandemic situation, a different treatment of practices is proposed for each one of these sections.

\section{CIRCUIT SIMULATION}

One of the objectives of the course is the simulation of digital and mixed circuits. As simulation software, PROTEUS (Labcenter Electronics) has been purchased and used.

This software allows schematic capture, interactive simulation, programming and debugging of programs for microcontrollers and microprocessors, and even the creation of printed circuit boards. The software is installed in the ETSID laboratories and is available for the students.

Adapting the practices to simulation has been simple thanks to Polilabs. This tool allows the students to access university-licensed programs from their personal computers, thus being able to carry out the practices remotely. 


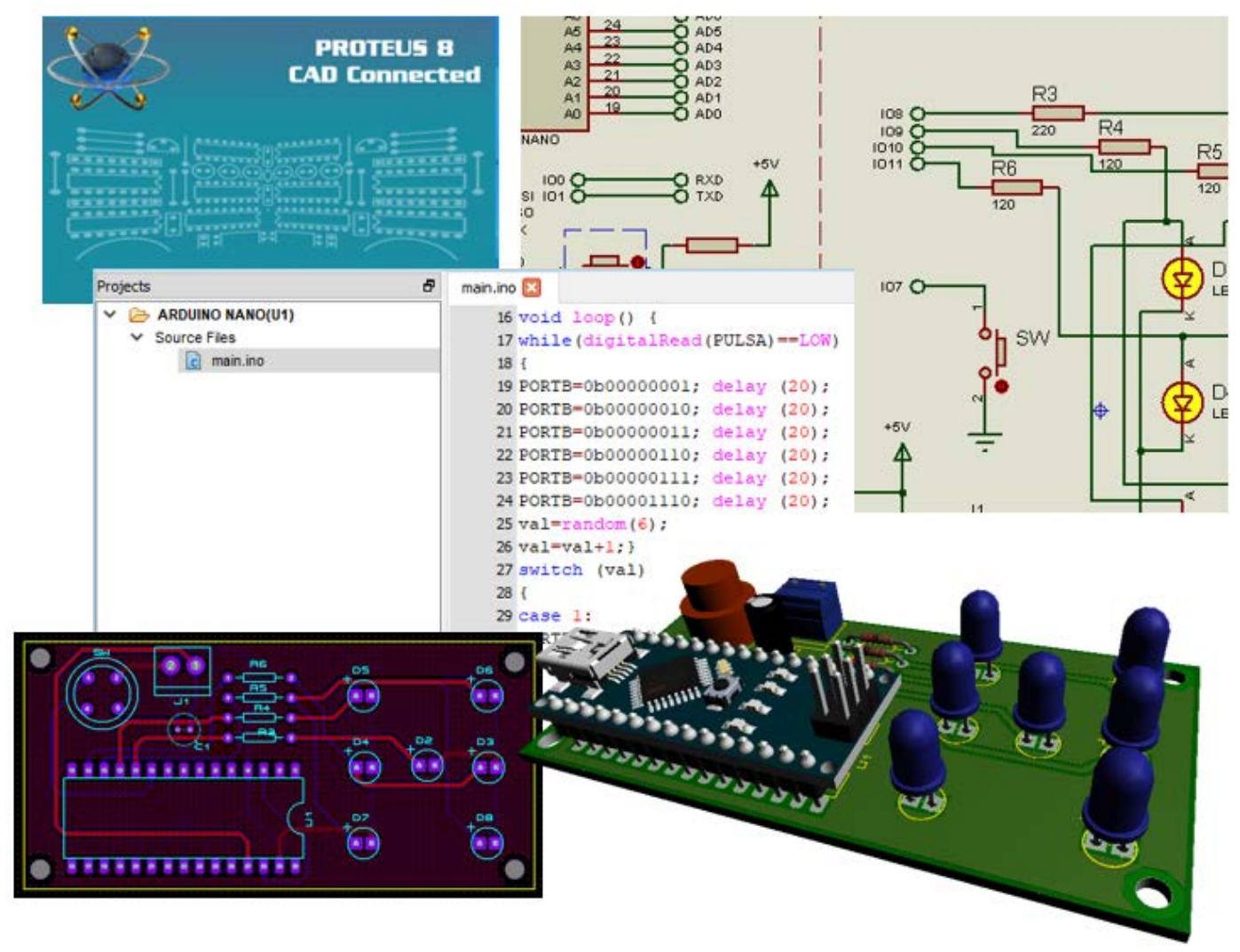

Figure 1. Proteus simulation environment.

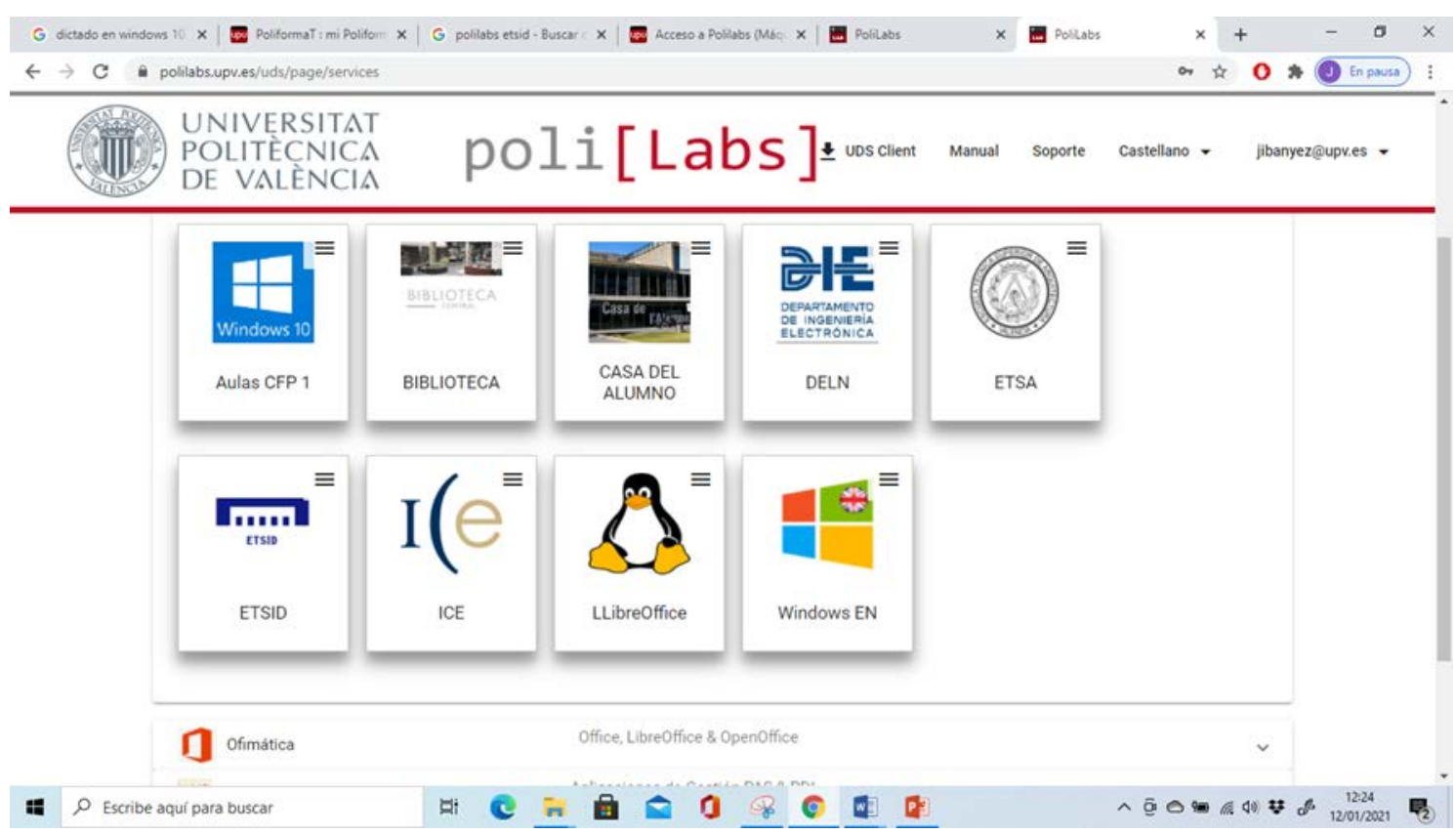

Figure 2. Polilab environment.

Simulation is an essential step in digital system design because it enables design verification and debugging prior to manufacturing. But simulation is based on models and, in certain cases, real prototypes cannot be replaced by practices. Thanks to Polilabs tool and Proteus, the students are able to carry out the scheduled practices in Digital Electronics from home during the complete period of confinement. 
Finally, a physical board with the necessary peripherals was designed in order to conduct practices in Section 2. The simulations corresponding to each exercise were carried out in the schematic of this board.

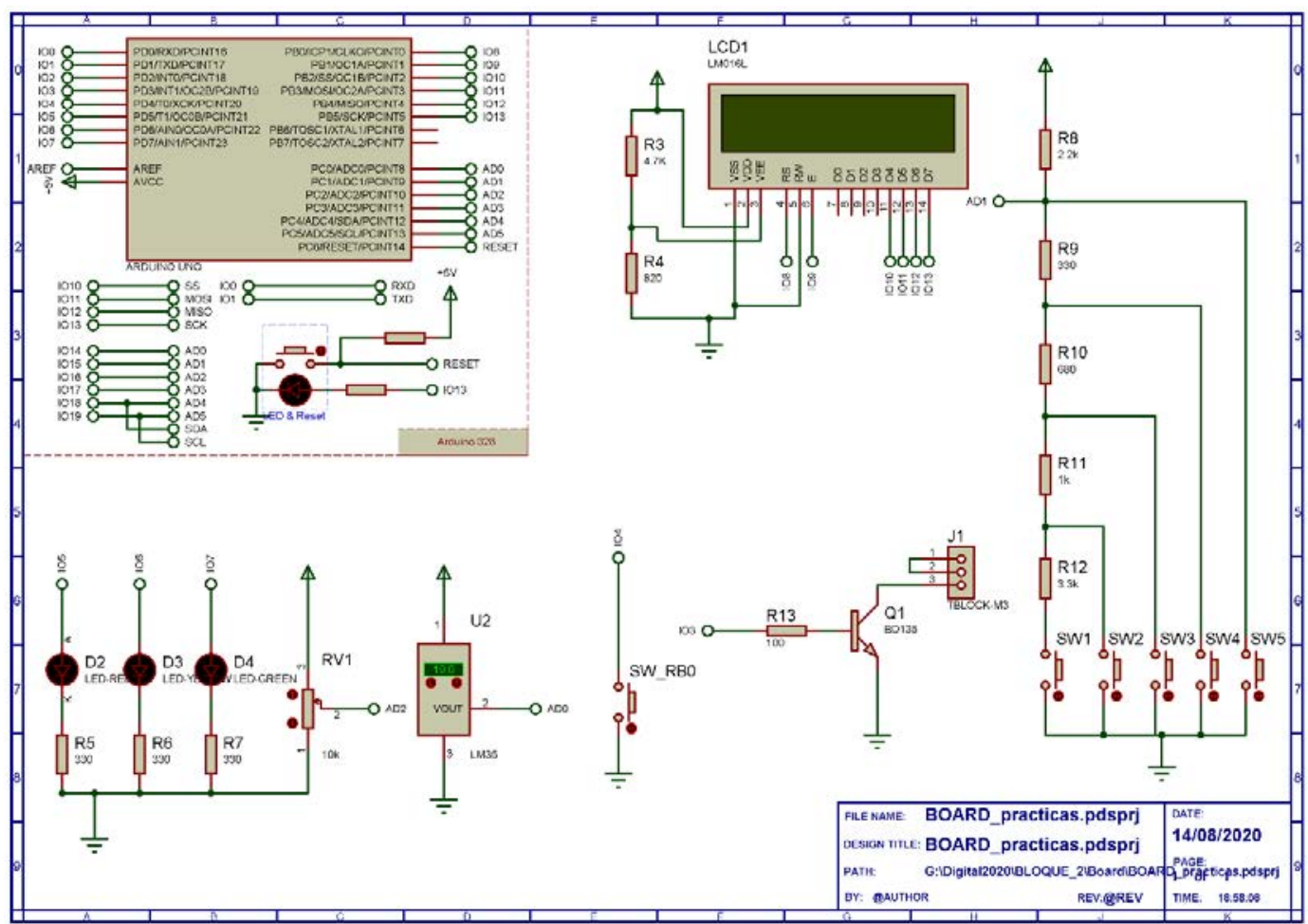

Figure 3. Scheme of the board used in the practices.

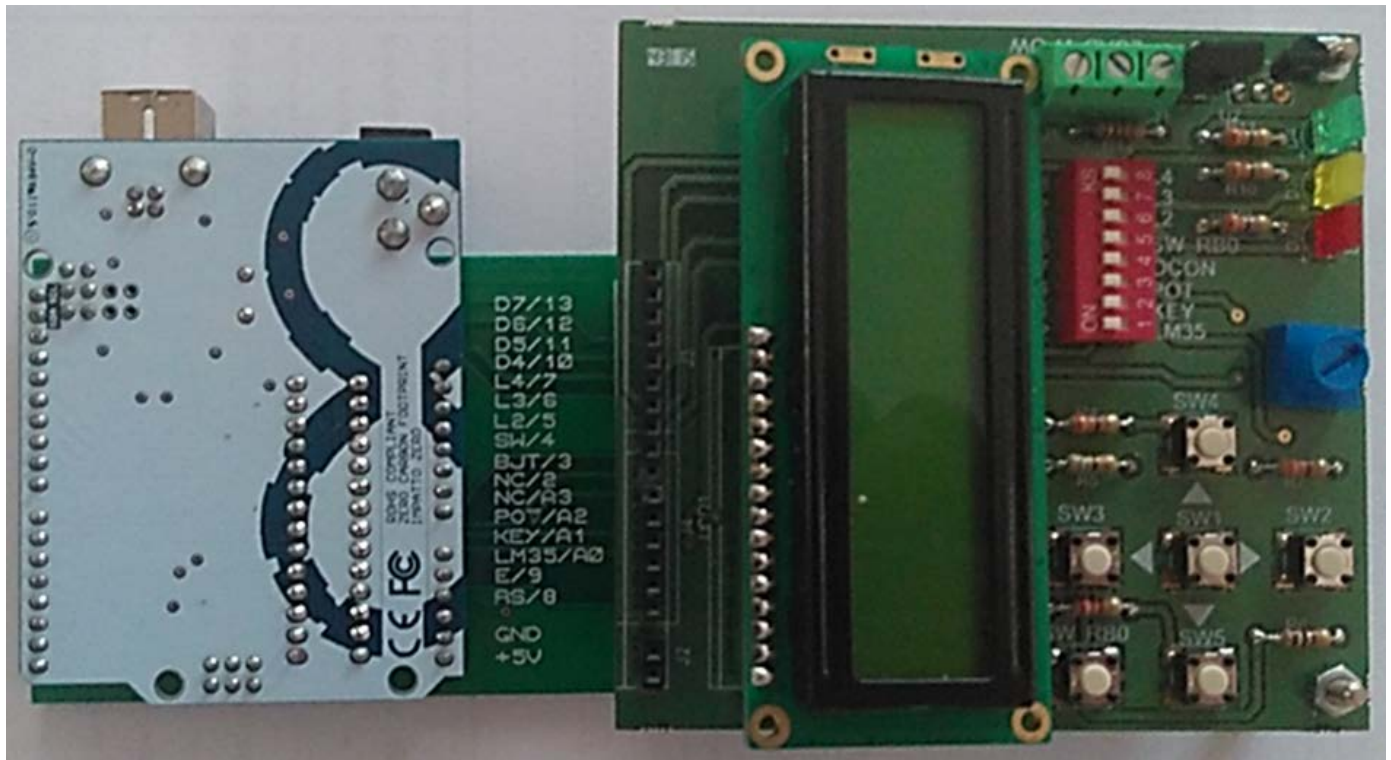

Figure 4. Real board used in the practices.

\section{RESULTS: THE REMOTELAB}

Even with the present difficulties, practices are scheduled to be face-to-face with limited capacity groups this course. As usually in the last years, practices will be carried out by couples of students because it allows to promote teamworking and a better information exchange between them. This last aspect is very important because it helps them to reinforce the acquired concepts and express them in a technical way to their respective mates. 
Facing this new scenario of partial assistance at class, it was suggested an alternative assistance model to the practices. The idea is to let one member of the couple physically assist to the session in the classroom as the other member attends to the session by streaming at home. Students would alternate their assistance role each week. This assistance model required an electronic board in which both, the students at home and those in the classroom can work simultaneously.

In order to achieve this goal, a remote desktop is used to facilitate the external connection. Thus, both students at home and students in the classroom can work with the laboratory computer and program their codes in a collaborative manner. This alternative requires the laboratory computer to have a webcam for on-line monitoring the development of the practice.

Up to here, nothing more should be done. But the practice board has actuators (push buttons and potentiometer) that cannot be activated remotely. To solve this problem, a control circuit with a digital potentiometer and controlled switches was added to the practice board, replacing the ones physically on the board. A small processing program makes the graphical interface that allows remote interaction with these switches and potentiometer.

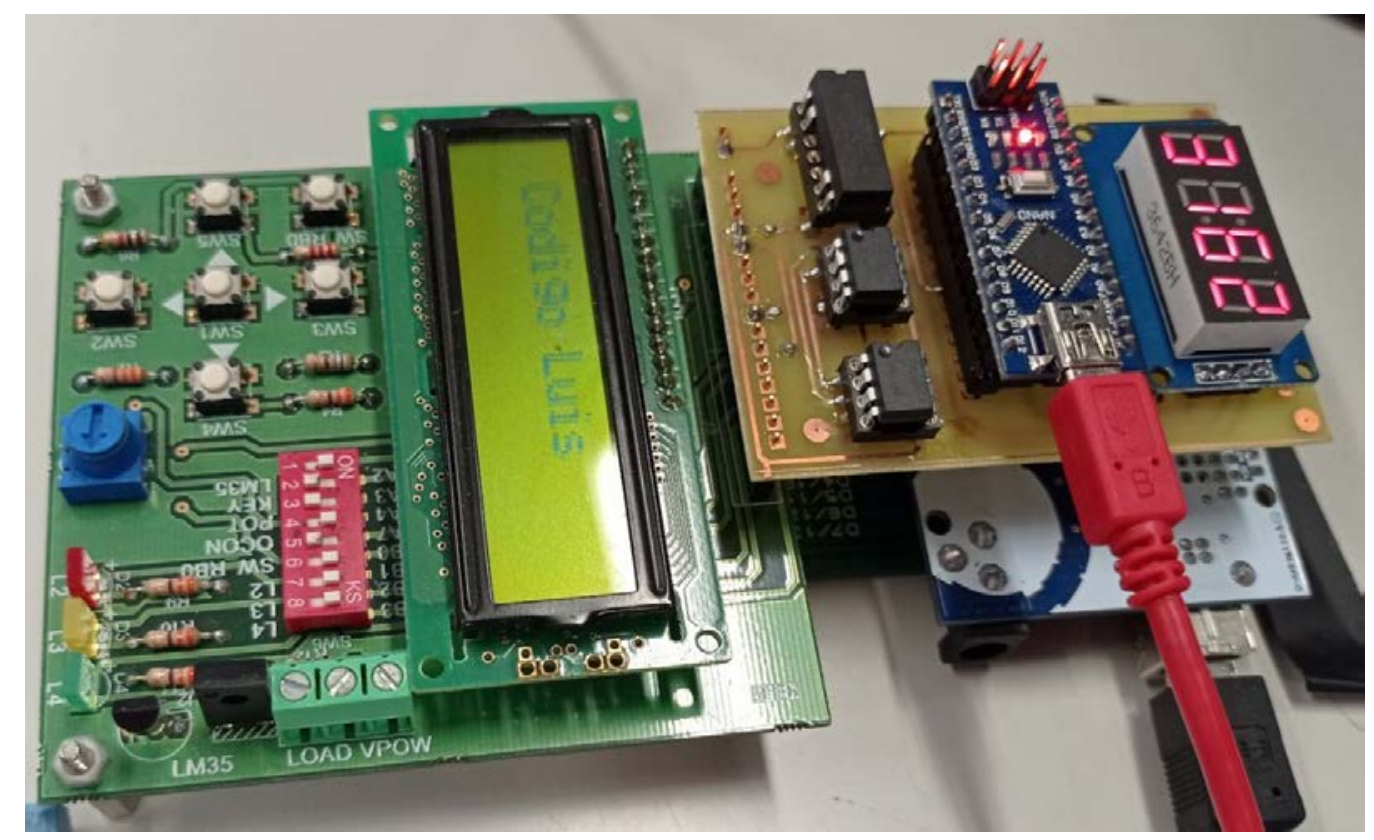

Figure 5. Practice board with a control card.

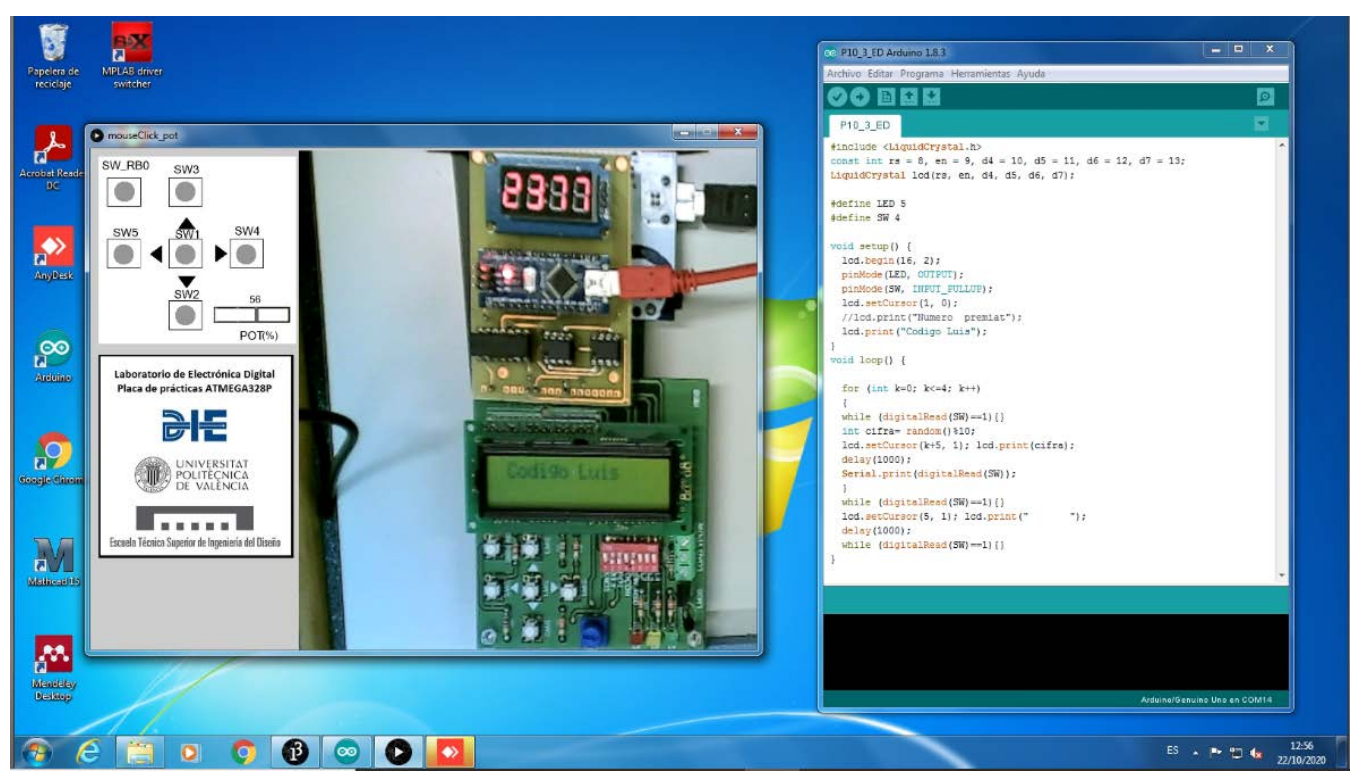

Figure 6. Remote desktop with programming window, webcam and actuators. 
A counter has been incorporated in the card as a control to check the correct communication. In this way, it can be assured that the images received at home by the students are showing what is actually happening in the laboratory.

\section{CONCLUSIONS}

It is not expected a return to a normal academic activity in the near future even vaccination programs are advancing, COVID-19 immunization will not become true before the end of the present year. Therefore, it is necessary to reconsider all the learning-teaching aspects in Higher Education to maintain the quality of Higher Education assuring the mandatory sanitary measures. Thus, theoretical sessions, tutorials and academic works can be given and monitored on-line. On the contrary, laboratory practices must be face-to-face teamworking activities in order to assure the effective education of our students. In the field of Digital Electronics, a real contact with electronic components, systems and measure devices is fundamental.

In this work, an alternative solution is introduced allowing both face-to-face and on-line virtual assistance to the practices. This proposal keeps the original working structure by couples of students but one of them working virtually at home and the other one face-to-face in the laboratory, with an alternative role session after session. This proposal would assure the active participation of the students in the practices of the subject Digital Electronics.

\section{REFERENCES}

[1] Cuenca, L., Alarcón, F., Boza, A., Fernández-Diego, M., Ruíz, L., Gordo, Ml., Poler, R., Alemany, M.M.E. (2015). "Rubric to assess the competence of innovation, creativity and entrepreneurship in bachelor degree." Book of abstracts of the ICIEOM-CIO- IIIE. Engineering Systems and Network: The way for industrial engineering and operations management. International Conference 2015 ISBN: 978-972-789-453-6.

[2] Cuenca, L., Alarcón, F., Boza, A., Fernández-Diego, M., Ruíz, L., Gordo, Ml., Poler, R., Alemany, M.M.E. (2015). "Rúbrica para la Evaluación de la Competencia Innovación, Creatividad y Emprendimiento en máster". Congreso In-Red 2015-Universitat Politècnica de València. ISBN: 97884-9048-396.

[3] Marín-García, J.A., Ramírez, L., Andreu, M.A. (2015). "Comparación de los métodos de escalas y frecuencia de comportamiento para valorar la competencia de innovación. El punto de vista de alumnos y profesor en el caso de una asignatura de máster". Congreso In-Red 2015-Universitat Politècnica de València.

[4] Villa, A. Y Poblete, M. (2007): Aprendizaje basado en competencias. Una propuesta para la evaluación de las competencias genéricas. Ediciones Mensajero. Bilbao.

[5] Ruíz, L., Gordo, M.L., Fernández- Diego, M., Boza, A., Cuenca, L., Alarcón, A., Alemany, M.M.E. (2015):" Implementación de actividades de aprendizaje y evaluación para el desarrollo de competencias genéricas: un caso práctico de aplicación de técnicas de Pensamiento de Diseño, y evaluación mediante rúbricas, de las competencias de Creatividad, Innovación y Emprendimiento". Congreso In-Red 2015 - Universitat Politècnica de València. ISBN: 978-84-9048-396-1.

[6] Ibáñez Civera,J., Laguarda-Miró,N., Gil Sánchez, L., Conesa Domínguez,C., Montes Robles, R., García-Breijo, E. (2007): "Assessing competences: innovation, creativity and entrepreneurship. The case of the competition car". 11th International Technology, Education and Development Conference (INTED 2017). 